\title{
Factors Affecting the Formation, Severity and Location of White Spot Lesions during Orthodontic Treatment with Fixed Appliances
}

\author{
Khaled Khalaf ${ }^{1}$ \\ ${ }^{1}$ Department of Orthodontics, University of Aberdeen, Aberdeen, United Kingdom.
}

\author{
Corresponding Author: \\ Khaled Khalaf \\ The University of Aberdeen Dental School and Hospital \\ Cornhill Road, Foresterhill, AB25 2ZR \\ Aberdeen \\ United Kingdom \\ Tel. +44 1224555151 \\ E-mail: k.khalaf@abdn.ac.uk
}

\begin{abstract}
Objectives: The purpose of the present study was to investigate factors affecting the formation, severity and location of white spot lesions in patients completing fixed appliance therapy.

Material and Methods: A total of 45 patients (19 males and 26 females, mean age 15.81 years, standard deviation 2.89 years) attending consecutively Aberdeen Dental Hospital (ADH) between January and June 2013 to have their fixed appliances removed were given a questionnaire to elicit information regarding their dental care and diet. They were then examined clinically as well as their pre-treatment photographs to record treatment data and white spot lesion (WSL) location and severity using a modified version of Universal Visual Scale for Smooth Surfaces (UniViSS Smooth). Absolute risk (AR) and risk ratios $(\mathrm{RR})$ were also calculated.

Results: The incidence of at least one WSL observed in patients was $42 \%$, with males displaying a higher incidence than females. The highest incidence of WSLs was recorded on the maxillary canines and lateral incisors, and on the maxillary and mandibular premolars and first molars. The gingival areas of the maxillary and mandibular teeth were the most affected surfaces. Significant $(\mathrm{P}<0.05)$ relationships were found between the presence of WSLs and the following factors: poor oral hygiene $(\mathrm{OH})$, males, increased treatment length, lack of use of fluoride supplements, use of carbonated soft drinks and/or fruit juices and the use of sugary foods. Poor $\mathrm{OH}$ posed the highest risk of developing WSL $(\mathrm{RR}=8.55)$.

Conclusions: $42 \%$ of patients have developed white spot lesions during fixed appliance therapy. Various contributing risk factors were identified with the greatest risk posed by a poor oral hygiene.
\end{abstract}

Keywords: dental white spot; fluoride; orthodontic wires; orthodontic brackets; risk factors; teeth.

Accepted for publication: 24 February 2014

To cite this article:

Khalaf K. Factors Affecting the Formation, Severity and Location of White Spot Lesions during Orthodontic Treatment with Fixed Appliances.

URL: http://www.ejomr.org/JOMR/archives/2014/1/e4/v5n1e4ht.pdf

doi: $10.5037 /$ jomr.2014.5104 


\section{INTRODUCTION}

A white spot lesion (WSL) is a mark of decalcification or demineralization of enamel, which appears as a white spot on tooth surfaces eluding to their name [1]. WSLs can affect any tooth in the dentition and occur on any area of the tooth surface. They signify the initial stage of tooth caries and are caused by the activity of bacterial plaque $[\underline{2}, \underline{3}]$. WSLs are particularly common problem during orthodontic treatment, and a continuous challenge faced by clinicians to prevent their occurrence [4]. The presence of fixed appliances on tooth surfaces such as brackets and bands creates difficulties in keeping teeth clean, leading to the build-up of plaque and WSL formation [5]. WSLs can interfere with orthodontic treatment and affect patients as a cosmetic problem post-orthodontic treatment [ $[$ ] Under normal circumstances, the balance of demineralization and remineralisation of enamel determines the formation of dental caries. Dental caries is caused by the activity of oral bacteria that forms as plaque on tooth surfaces, also known as dental biofilm, and are responsible for producing organic acids by metabolism of carbohydrates in the mouth $[1,7,8]$. The metabolism of carbohydrates, notably sugars from food result in the production of an acidic, low $\mathrm{pH}$ environment $[9, \underline{10}]$. These acids diffuse into tooth enamel and dissolve the layers of calcium and phosphate hydroxyapatite crystals [2, $\underline{9}$, leading to lesions on the enamel surface. Furthermore, plaque itself acts as a barrier that prevents acids from diffusing away from the local environment [1]. The lesions created by demineralization can be arrested from progressing and reversed by calcium, phosphate and fluoride minerals present in saliva, which diffuse back into the porous subsurface region of the carious lesion, which form new layers in the enamel, termed remineralisation $[1,2, \underline{11}, \underline{12}]$. This balance of damage and repair occurs naturally, constantly on-going and occurs numerous times daily in the mouth [2].

If a disruption of this balance has occurred in favour of demineralization, this would lead to the permanent formation of white spot lesions that can progress into cavities and can no longer be reversed [ $\underline{3}$ ]. Tipping the balance back toward remineralisation would arrest the progression of WSLs [11], although they remain as cosmetic scars []․

Various risk factors can contribute to the development of WSLs. These are poor oral hygiene, low salivary volume and a sugary diet, which all promote the proliferation and activity of bacterial plaque $[\underline{1}, \underline{13}]$.

Although WSLs occur in caries development irrespective of orthodontic treatment, it is during orthodontic treatment that they are extremely common [4]. The brackets, bands, archwires and elastomeric modules of fixed orthodontic appliances provide additional surface area for bacteria to develop and thus accelerate the accumulation of plaque and the formation of lesions in areas that would normally have a low risk of caries [13]. This is especially so when combined with a poor oral hygiene $(\mathrm{OH})[12,14]$. The levels of oral bacteria have been reported to increase five folds upon the application of fixed bonds [1]. The increased time and difficulty of maintaining good oral hygiene during orthodontic treatment are challenges faced by patients, as the use of dental floss, interdental brushes and good tooth brushing techniques requires greater effort.

There have been many studies into the incidence of WSLs with varying results. Studies have reported incidence from $23 \%$ to $97 \%$ of patients present at least with one white spot lesion when assessed immediately after fixed appliance debonding at completion of treatment $[1, \underline{13}, \underline{15-20}]$. This high variation seen may be due to differences in the methods of lesion quantification (visual scale or imaging analysis), local attitudes toward dental health, treatment length and individual risk factors of patients, such as $\mathrm{OH}$ and diet in the studied groups. The anterior maxillary teeth were found to be the most affected, with studies reporting the highest incidence of WSLs on the maxillary lateral incisors, located on the gingival margin $[\underline{14}, \underline{15}, \underline{20}]$. In a 5-year follow-up study by Ogaard, 1989 [16], WSLs were still observed as a cosmetic problem for orthodontic patients. Similar findings were published in a 12-year follow-up study by Shungin et al. [] examining patients who had incidences of WSLs during orthodontic treatment. They found that although the size of the lesions were reduced over time, they still presented a cosmetic problem for many orthodontic patients as scars on their teeth even 12 years after treatment.

Although WSLs are a common problem in orthodontic patients, they can be prevented by addressing their risk factors including diet restriction and good $\mathrm{OH}[\underline{2}, \underline{12}]$, and use of fluoride. The benefits of fluoride come from its ability to reduce the solubility of enamel once incorporated into its surface [22], slow the progression of any carious lesion by promoting remineralisation of the region and reducing the rate of transport of soluble minerals out of tooth enamel in an acidic environment, by forming fluoridated hydroxyapatite crystals on the enamel surface [23]. Fluoridated hydroxyapatite also hardens tooth enamel, making it more resistant to caries formation [24]. However, fluoride alone cannot overcome a high bacterial challenge [2]. The delivery of fluoride can occur through commercially 
available products such as toothpaste, mouthwash and dissolving tablets, while other fluoride sources include varnishes, and fluoridation of public water supply [25]. The use of fluoride supplements is regularly recommended by multiple studies to prevent WSLs and tooth decay due to the overwhelming beneficial evidence. Fluoride prescription has been shown to lower the prevalence of WSLs in patients undergoing orthodontic treatment compared to patients that did not use fluoride or only used it sparingly $[\underline{15}, \underline{24}, \underline{26}, \underline{27}]$. An in-depth systematic review by Benson et al. [4] on the use of fluoride to counteract demineralization during orthodontic treatment concluded that there were links between supplementary exposure to fluoride and the lower occurrence and severity of white spot lesions, and recommended daily use of fluoride mouthwash to lower the risk of WSLs development, although noted more research was needed into the effectiveness of different fluoride delivery methods.

A few studies have reported some risk factors of the formation of WSLs, but none to date have evaluated all the factors contributing to the incidence, severity and location of WSLs. Therefore, the purpose of the present study was to investigate factors affecting the formation, severity and location of white spot lesions in patients completing fixed appliance therapy.

\section{MATERIAL AND METHODS Study sample}

This is a cross-sectional analytical study of a sample of forty five patients who attended Aberdeen Dental Hospital consecutively to have their fixed appliances removed between January and June 2013. Inclusion criterias were: patients who were treated orthodontically. Non-Caucasian patients, patients who have had previous orthodontic treatment, patients with congenital abnormalities or systematic medical conditions were excluded from the study. Consent was sought and obtained from all patients on the day of their fixed appliances removal.

\section{Study design}

Patient's data collection was made using a data sheet that was developed to record the incidence of WSLs and contributing factors. The collection sheet was designed to collect data anonymously in two parts, first to survey patients before their admission into the surgery regarding their contributing factors to WSLs i.e. dental care and diet, including use of fluoride supplements, use of carbonated soft drinks and/or fruit juices and use of sugary foods. Once in the surgery, the second part of the data collection sheet commenced by examining patients for the presence, location and severity of WSLs using the initial patient photographs as pre-treatment comparison record. Additional treatment data was recorded from the patient's dental notes.

WSL examination took place by an experienced and trained clinician, where the tooth surfaces were pumiced, cleaned with water to remove any adhesive residue and debris and dried with compressed air before inspection under a dental lamp. Examination of the buccal/labial tooth surfaces occurred in a systematic manner, starting with the maxillary left first molar, and continuing until the maxillary right first molar followed by the same pattern in the mandibular arch.

Following WSL inspection and recording, additional treatment data was obtained from the patient's dental record including age, genders, treatment length and state of the $\mathrm{OH}$. The state of $\mathrm{OH}$ was recorded as either adequate or inadequate. Inadequate $\mathrm{OH}$ was recorded if the patient failed to achieve an adequate $\mathrm{OH}$ in 4 or more occasions when seen to adjust their fixed appliances.

WSL severity and location was recorded on a schematic diagram representing the maxillary and mandibular buccal/labial surfaces of the first molars, first and second premolars, canines, lateral incisors and central incisors. The schematic diagram contained reference lines illustrating the surface aspects of each tooth: central, mesial, distal and gingival margin. The central aspect was located where the orthodontic bracket was bonded, mesial and distal sides were located to either side of the central surface, and the gingival aspect was located toward the gingival margin.

If WSLs were observed, the location was drawn onto the diagram and its corresponding severity $(1,2,3$ or 4) was noted beside it. A caries severity scale was kept on hand as a reference for classifying WSLs. The severity scale was modified from Universal Visual Scoring System (UniViSS); a visual analogue scale developed by Kuhnisch et al. [28]. The scale was developed with influences from key publications, International Caries Detection and Assessment System (ICDAS) and the World Health Organization (WHO) to potentially standardize the development of carious lesions for accurate classification, in order to address current issues with many other visual diagnostic scales such as validity and reproducibility [28]. Two variants exist, one for occlusal surfaces and another for smooth surfaces. As orthodontic appliances are fixed onto the smooth labial and buccal surfaces of teeth, UniViSS for smooth surfaces was chosen, as importantly, it was a clear and simple visual analogue scale with image references to classify WSLs from their early development to the formation of cavities and tooth 
Table 1. Modified Universal Visual Scoring System for smooth surfaces (UniViSS smooth)

\begin{tabular}{|c|c|c|c|c|}
\hline \multirow{3}{*}{ Discoloration } & \multicolumn{4}{|c|}{ Lesion detection and severity assessment } \\
\hline & $\begin{array}{l}\text { First visible signs of } \\
\text { a caries lesion }\end{array}$ & Established caries lesion & $\begin{array}{c}\text { Microcavity and/ } \\
\text { or localised enamel } \\
\text { breakdown }\end{array}$ & $\begin{array}{l}\text { Dentin } \\
\text { exposure }\end{array}$ \\
\hline & Score 1 & Score 2 & Score 3 & Score 4 \\
\hline Sound surface & \multicolumn{4}{|c|}{ No cavitations and/or discolorations are detectable. } \\
\hline White spot & $\begin{array}{l}\text { First white spot lesions are } \\
\text { unobtrusive and will be } \\
\text { detected after prolonged air } \\
\text { drying ( } \sim 5 \text { seconds }) \text {. }\end{array}$ & $\begin{array}{l}\text { White spot lesions are detectable without } \\
\text { prolonged air drying. Air drying improves } \\
\text { the assessment of the surface texture } \\
\text { (smooth versus rough) }\end{array}$ & \multirow{3}{*}{$\begin{array}{l}\text { Pathological enlargements } \\
\text { are detectable with } \\
\text { or without enamel } \\
\text { breakdowns - visible as } \\
\text { interruption of the surface } \\
\text { continuity. No dentin } \\
\text { exposure is evident. } \\
\text { Enlargements }>0.5 \mathrm{~mm} \\
\text { (use the ball point of the } \\
\text { CPI probe) may indicate a } \\
\text { microcavity. }\end{array}$} & \multirow{3}{*}{$\begin{array}{l}\text { Dentin } \\
\text { exposure } \\
\text { is } \\
\text { detectable. }\end{array}$} \\
\hline White-brown & $\begin{array}{l}\text { White-(caramel-) brown } \\
\text { lesions will be detected } \\
\text { with prolonged air drying } \\
\text { ( } \sim 5 \text { seconds). Brown areas } \\
\text { are in most cases visible } \\
\text { without air-drying. }\end{array}$ & $\begin{array}{l}\text { White-(caramel-) brown lesions are } \\
\text { detectable without prolonged air drying. } \\
\text { Air drying improves the assessment of the } \\
\text { surface texture, which indicates in most } \\
\text { cases a rough lesion. The brown spot is } \\
\text { surrounded by white demineralisations. }\end{array}$ & & \\
\hline Brown (dark) & $\begin{array}{l}\text { Small brown spot lesions } \\
\text { will be detected even } \\
\text { without air drying. }\end{array}$ & $\begin{array}{l}\text { Brown discoloured lesions are always } \\
\text { detectable without prolonged air drying. }\end{array}$ & & \\
\hline $\begin{array}{c}\text { Greyish } \\
\text { translucency }\end{array}$ & \multicolumn{4}{|c|}{ Not detectable } \\
\hline
\end{tabular}

decay. The scale was then modified by simplifying the severity scale for use in this study (Table 1). The scale used in the study was as follows:

1. Class 1 - First visible signs of a caries lesion;

2. Class 2 - Established caries lesion;

3. Class 3 - Microcavity and/or localised enamel breakdown;

4. Class 4 - Dentin Exposure.

\section{Statistical analysis}

Cohen's kappa statistics was used to assess the agreement between two examiners recording the presence/absence of WSL of 20 randomly selected patients. Pearson Chi-Square test was used to assess the statistical significance of the differences of the presence/ absence of WSLs between different risk groups. When $>20 \%$ of the expected cells has frequencies less than 5 the Fisher-Freeman-Halton Test was used. The absolute risk (AR) and risk ratio (RR) of developing WSL was also calculated.

\section{RESULTS}

The study sample consisted of 26 females (mean age \pm standard deviation $(\mathrm{SD})=15.69 \pm \mathrm{SD} 2.88$ years $)$ and 19 males (mean age $\pm \mathrm{SD}=15.97 \pm \mathrm{SD} 2.98$ years). Sixty five percent of females (17 patients) were $<18$ years old and the remaining ( 9 patients) were $\geq 18$ years whereas in males $63 \%$ ( 12 patients) were $<18$ years old and the remaining ( 7 patients) were $\geq 18$ years.
The inter-rater agreement for the presence/ absence of WSLs was found to be near perfect $($ Kappa $=0.82[\mathrm{P}<0.001])$. The incidence of WSLs at Aberdeen Dental Hospital was $42 \%$, where 19 out of 45 patients were observed with at least one WSL. For further analysis of possible contributing factors, the patients were divided into gender and age groups. The incidence of WSLs in males was significantly higher than females ( $\mathrm{P}<0.001)$. In females, $23 \%$ ( 6 out of 26 patients) were observed with at least 1 WSL compared to males at $68 \%$ (13 out of 19 patients) (Table 2). The RR of developing WSL in males compared with females was 2.96 indicating that males were almost 3 times more likely to form WSLs compared with females. The incidence of WSLs was twice in teenagers (age under 18 years) compared to adults (age 18 years and over) with corresponding incidences of $52 \%$ and $25 \%$ respectively (Table 2 ). However, the differences were not statistically significant $(P>0.05)$. The $R R$ of developing WSL in teenagers compared with adults was 2.08 indicating that teenagers were twice at risk of developing WSL more than adults.

Ninety seven percent of the WSLs were of grade 1 severity and the remaining 3\% were of grade 2 severity and none of the WSLs scored grade 3 or 4 severity.

There was a symmetry in the incidence of WSLs. The maxillary anterior teeth were statistically significantly $(P<0.05)$ more affected than the mandibular anterior teeth. The range of the number of WSLs for the maxillary anterior teeth was $9-14$ whereas for the mandibular anterior teeth was 2 - 4. The maxillary lateral incisors and canines are the most affected teeth 
Table 2. Distribution of patients with and without white spot lesion (WSL) depending on the associated risk factors

\begin{tabular}{|c|c|c|c|c|}
\hline \multicolumn{2}{|l|}{ Factor } & $\begin{array}{c}\text { In group number (\%) } \\
\text { with WSL }\end{array}$ & $\begin{array}{c}\text { Total number }(\%) \text { of } \\
\text { group }\end{array}$ & Test and P-value \\
\hline \multirow{2}{*}{ Gender } & Female & $6(23)$ & $26(100)$ & \multirow{2}{*}{$\begin{array}{l}\text { Pearson Chi-Square (12.583), } \\
\qquad \mathrm{P}<0.001^{\mathrm{a}}\end{array}$} \\
\hline & Male & $13(68)$ & $19(100)$ & \\
\hline \multirow{2}{*}{ Age } & $<18$ years & $15(52)$ & $29(100)$ & \multirow{2}{*}{$\begin{array}{l}\text { Pearson Chi-Square (3.019), } \\
\qquad \mathrm{P}>0.05\end{array}$} \\
\hline & $\geq 18$ years & $4(25)$ & $16(100)$ & \\
\hline \multirow{3}{*}{ Treatment length } & $<24$ years & $3(20)$ & $15(100)$ & \multirow{3}{*}{$\begin{array}{l}\text { Fisher-Freeman-Halton } \\
\text { Test (9.13), } \mathrm{P}<0.05^{\mathrm{b}}\end{array}$} \\
\hline & $24-36$ months & $5(33)$ & $15(100)$ & \\
\hline & $>36$ months & $11(73)$ & $15(100)$ & \\
\hline \multirow{2}{*}{ OH level } & Adequate & $3(11)$ & $28(100)$ & \multirow{2}{*}{$\begin{array}{c}\text { Pearson Chi-Square }=30.16, \\
\qquad \mathrm{P}<0.001^{\mathrm{a}}\end{array}$} \\
\hline & Inadequate & $16(94)$ & $17(100)$ & \\
\hline \multirow{4}{*}{$\begin{array}{l}\text { Use of fluoride supplements } \\
\text { (with regards to treatment) }\end{array}$} & None & $13(93)$ & $14(100)$ & \multirow{4}{*}{$\begin{array}{l}\text { Fisher-Freeman-Halton } \\
\text { Test (33.32), } \mathrm{P}<0.001^{\mathrm{b}}\end{array}$} \\
\hline & Before & $4(80)$ & $5(100)$ & \\
\hline & During & $2(17)$ & $12(100)$ & \\
\hline & Both & $0(0)$ & $14(100)$ & \\
\hline \multirow{4}{*}{$\begin{array}{l}\text { Use of carbonated soft } \\
\text { drinks and/ or fruit juices } \\
\text { (times per week) }\end{array}$} & 1 & $3(20)$ & $15(100)$ & \multirow{4}{*}{$\begin{array}{l}\text { Fisher-Freeman-Halton } \\
\text { Test (13.72), } \mathrm{P}<0.005^{\mathrm{b}}\end{array}$} \\
\hline & 2 & $3(25)$ & $12(100)$ & \\
\hline & 3 & $7(58)$ & $12(100)$ & \\
\hline & $\geq 4$ & $6(100)$ & $6(100)$ & \\
\hline \multirow{4}{*}{$\begin{array}{l}\text { Use of sugary foods } \\
\text { (times per week) }\end{array}$} & 1 & $4(27)$ & $15(100)$ & \multirow{4}{*}{$\begin{array}{l}\text { Fisher-Freeman-Halton } \\
\text { Test (13.57), } \mathrm{P}<0.005^{\mathrm{b}}\end{array}$} \\
\hline & 2 & $4(33)$ & $12(100)$ & \\
\hline & 3 & $3(30)$ & $10(100)$ & \\
\hline & $\geq 4$ & $8(100)$ & $8(100)$ & \\
\hline
\end{tabular}

$\mathrm{OH}=$ oral hygiene.

aStatisticaly significant, Pearson Chi-Square test.

${ }^{b}$ Statisticaly significant, Fisher-Freeman-Halton test.

followed in descending order by the maxillary and mandibular premolars and first molars, the maxillary central incisors, mandibular canines and mandibular incisor teeth.

With regards to the location of WSLs on tooth surfaces, it was found that the most affected location in both dental arches was the gingival margin. However, WSLs were located in all areas of the maxillary teeth, but almost all WSLs were exclusively recorded on the gingival margin of the mandibular teeth.

When assessing the impact of treatment length on the formation of WSLs there were statistically significant differences between the 3 treatment length groups compared: $<24$ months, $24-36$ months and $>36$ months $(\mathrm{P}<0.05)$. The RR of forming WSLs in the treatment length groups $24-36$ months and $>36$ months compared with the $<24$ months group was 1.65 and 3.65 respectively. This means that the 24 36 months group was 1.65 times and the $>36$ months group was 3.65 times more likely to form WSLs than the $<24$ months group (Table 2).

Comparison of the incidence of WSLs between those who had adequate and inadequate $\mathrm{OH}$ level revealed a statistically significant difference $(\mathrm{P}<0.001)$ with those who had inadequate $\mathrm{OH}$ were 8.55 times more likely to have WSLs than those with adequate $\mathrm{OH}$. The AR for the adequate $\mathrm{OH}$ group was 0.11 whereas the corresponding figure for the inadequate OH group was 0.94 (Table 2).

Statistically significant $(\mathrm{P}<0.001)$ differences in the occurrences of WSLs were found between those who had fluoride supplements during the orthodontic treatment and those who either never had it or had it only before the start of orthodontic treatment (Table 2). Patients who never had fluoride supplements or only had it before the orthodontic treatment were 5.47 and 4.71 times respectively more likely to form WSLs than those who regularly had fluoride supplements during the orthodontic treatment. The corresponding ARs for those who never had fluoride supplements, those who had them only before the orthodontic treatment and those who had them during the orthodontic treatment were $0.93,0.80$ and 0.17 .

Statistically significant $(\mathrm{P}<0.005)$ differences in the formation of WSLs were found between those who used carbonated soft drinks and/or fruit juices once or twice a week and those who used them 3 and 4 times or more a week (Table 2). The ARs for those who used 
carbonated soft drinks and/or fruit juices once, twice, three times, four times or more a week were $0.20,0.25$, 0.58 and 100 respectively.

Statistically significant $(\mathrm{P}<0.005)$ differences in the formation of WSLs were also found among patients depending on the frequencies of their usage of sugary foods (Table 2), with the differences found mainly between those who used sugary foods 4 or more times and the remaining groups. The ARs for those who used sugary foods once, twice, three times, four times or more a week were $0.27,0.33,0.3$ and 100 respectively.

\section{DISCUSSION}

The incidence of WSL found in the present study was $42 \%$ which falls in the mid-range of the reported figures in the previous literature. This figure compares well with the figures reported by Tufekci et al. [18] and Lucchese and Gherlone [20]. Tufekci et al. [18] reported a prevalence of $46 \%$ in a similar sample size of patients ( 37 patients), and Lucchese and Gherlone [20] reported a prevalence of $40 \%$ among patients who had been treated for 6 months, a figure which was increased to $43 \%$ among those who had been treated for 12 months. However, authors of the latter two studies have assessed the presence of WSLs using direct visual assessment method during orthodontic treatment, thus probably underestimating the reported incidence due to the difficulty of ascertaining the presence of a WSL. Some previous studies that reported lower incidence than that in the current study have evaluated either only the maxillary anterior teeth [1] $]$ or only the maxillary and mandibular anterior teeth [27], or used only photographic evaluation to assess the presence of WSL [30]. The highest incidence of WSLs reported in the previous literature (97\%) [19] was probably due to the early identification of the presence of WSLs that were not clinically visible as this study used quantitative light-induced fluorescence (QLF) to evaluate the presence of WSLs.

The present study found a symmetry in the incidence of WSLs as in many previous studies $[13,15,16,19,29]$. The maxillary anterior teeth were statistically significantly $(\mathrm{P}<0.005)$ more affected than the mandibular anterior teeth, a finding which agrees with previous investigations [29-31]. With regards to the most affected teeth, it was found in the present study that the maxillary canines were the most affected teeth followed by the maxillary lateral incisors. Similar findings were found by several previous investigators who have reported the most affected teeth to be either the maxillary canines $[\underline{16}, \underline{19}]$ or the maxillary lateral incisors $[\underline{13}, \underline{14}, \underline{15}, \underline{29}]$. However, some studies have reported different results, where the greatest number of WSLs was recorded on the maxillary first molars [16]. Only one study has found no differences in the incidence of WSLs between tooth types [18]. This may be attributed to the small sample size, relatively short follow-up period (12 months) and the evaluation of the WSLs while the fixed appliances were still present which would have made it more difficult to identify the mild forms of WSLs.

In contrast to the maxillary arch, posterior teeth (the first molars and premolars) were the most affected teeth in the mandibular arch. A study by Artun and Brobakken [14] found mandibular canines and premolars to be the most affected teeth instead. The distribution pattern of WSLs observed in the maxillary and mandibular teeth may be explained by different amounts of exposure of saliva to the maxillary anterior teeth in contrast to other areas of the dentition, or simply by poor tooth brushing techniques resulting in the ineffective cleaning of certain teeth.

Another contrast in the distribution of WSLs between the maxillary and mandibular arches was found in regards to the location of WSLs on tooth surfaces, where WSLs were found in all areas of the maxillary teeth, but almost all WSLs were exclusively recorded on the gingival margins of the mandibular teeth. However, the gingival margin was the most frequently recorded surface location of WSLs on both the maxillary and mandibular teeth. The gingival margin, located on the cervical third of the tooth where the tooth and gingiva meet is a common area for bacterial growth [1], and was the area where the most WSLs were seen. Accordingly, studies have also reported that WSLs commonly affect the gingival areas $[\underline{14}, \underline{15}, \underline{31}]$. The predominant location of WSLs on the gingival margins of the posterior mandibular teeth found in this study was interesting and unexpected. A possible explanation may primarily be due to the natural positioning of the posterior mandibular teeth with their clinical crowns are lingually inclined, unlike the maxillary teeth which have clinical crowns that sit centrally on their roots. This incline may mean that the lower, gingival areas of the mandibular teeth may be missed while brushing, which may be exacerbated by the presence of a large orthodontic bracket fixed on the buccal tooth surface, leading to bacterial build up and the formation of WSLs.

With regards to differences between genders it was found in the current study that males had significantly greater incidence of WSLs than females. There were discrepancies between previous studies in the reported incidence of WSLs with regards to genders. Some studies have reported similar findings to our investigation $[\underline{13}, \underline{18}, \underline{19}]$ and others reported 
no statistically significant $(\mathrm{P}>0.005)$ differences between genders although males tended to have greater incidence than females $[\underline{16}, \underline{17}, \underline{20}, \underline{29}, \underline{30}, \underline{32}]$. This gender difference may be due to the commonly reported better $\mathrm{OH}$ standards in females than in males [33-35].

Adolescent patients in the current study were found to be as twice as more likely to develop WSLs as adult patients, but the differences between the 2 age groups were not statistically significant $\mathrm{P}$, a finding which was also reported by Chapman et al. [13].

In the current study treatment length did impact on the formation of WSLs and it was found as the treatment length increased from $<24$ months to $>36$ months the likelihood of formation of WSLs did increase by 3.65 times. Tufekci et al. [18] and Lucchese and Gherlone [20] showed that WSLs can be prevalent in patients undergoing orthodontic treatment for as early as 6 months (38\% and $40 \%$ respectively), which increases with longer treatment duration at 12 months $(46 \%$ and $43 \%$ respectively), supporting the idea that the presence of fixed orthodontic appliances and greater treatment lengths serve as a risk factor for WSLs formation [ $\underline{5}$ ]. Similar finding was also reported by Chapman et al. [13] and Julien et al. [29], but Lovrov et al. [30] were unable to find an impact of the treatment length on the prevalence of WSLs.

$\mathrm{OH}$ level was found to have a significant correlation with the formation of WSLs whereby those who had inadequate $\mathrm{OH}$ were 8.5 times more likely to develop WSLs than those with adequate $\mathrm{OH}$. This has also been reported by several previous investigators who used different methods of assessing the $\mathrm{OH}$ level $[\underline{13}, \underline{19}, \underline{29}, \underline{30}]$. Furthermore, Julien et al. [리 ] evaluated the impact of the change in the $\mathrm{OH}$ level during treatment on the development of new WSLs and found that $59 \%$ of those whose $\mathrm{OH}$ have worsened during treatment have developed WSLs during treatment compared with only $20 \%$ of those whose $\mathrm{OH}$ stayed the same or got better during treatment developed new WSLs during treatment.

Fluoride supplements investigated in this study included fluoride mouthwash, fluoride tablets, fluoride varnishes and the intake of fluoridated water. The water supply in Aberdeenshire and Scotland in general are not fluoridated, with only rural Morayshire in Scotland receiving natural water fluoridation [25]. Additionally, all patients were unaware of water fluoridation during their childhood, regardless of where they lived during their childhood. No patients used fluoride tablets or varnishes, therefore only the use of normal antibacterial mouthwash containing fluoride was examined as a source of fluoride use.

As might be expected regular use of fluoride mouthwash during the orthodontic treatment did significantly reduce the risk of developing WSLs. Strateman and Shannon [하] reached the same conclusion following their study of 209 patients divided into 2 groups, the first (110 patients) who used fluoride gel regularly and the second group (99 patients) have used no fluoride and found corresponding incidence of WSLs of $27 \%$ and $59 \%$ respectively. It was also found that the daily use of 0.05 sodium fluoride mouthrinse reduced the incidence of decalcification during orthodontic treatment [37]. A study by Hadler-Olsen et al. [27] found that patients who received fluoride supplements and good patient compliance displayed a lower incidence of WSLs after orthodontic treatment than a control group that did not receive any fluoride supplements. Similarly, O'Reilly and Featherstone [24] illustrated that patients who used a combination of commercially available fluoride products had hardened enamel and inhibition of demineralization, compared to those that used little or no fluoride products at all.

However the incidence of WSLs reported in previous studies on patients who used daily fluoride rinse ranges from $11 \%$ to $89 \%[14,16,30-32]$. This reported wide range and discrepancies between those studies can be explained by the fact that previous research into the use of fluoride involved only asking patients about the use of mouthwash before and during treatment, or both limiting the responses to yes/no answers. Due to the wide time span covered, an important factor such as the regularity and frequency of fluoride use was not determined in those studies. Furthermore there may well have been significant discrepancies between those studies in terms of patient's compliances with the use of regular fluoride. A systematic review into the benefits of fluoride use during orthodontic treatment by Benson et al. [4] recommended the use of fluoride mouthwash, but stressed that beneficial effects would only be seen if used regularly, not sparingly.

Diet is a strong contributing factor to the development of WSLs and tooth decay, with a poor diet high in sugar increases the activity of bacterial plaque, raising the risk of WSLs formation [12]. It is also complex to study, due to different diets and the variety of food available, thus, has not been studied extensively in relation to orthodontic treatment. Thus, only sugary foods were investigated.

The use of carbonated soft drinks and/or fruit juices 4 times or more a week has significantly increased the risk of developing new WSLs compared with less frequent usages of such beverages. It has been shown that soft drinks adhere to enamel more readily and for a longer period than saliva, thus allowing plaque accumulation and growth and sugar metabolism resulting in enamel decalcification [38]. Furthermore, it was also shown 
that the frequency of consumption of soft drinks and especially between meals was correlated with greater decayed/missing/filled teeth (DMFT) scores [39] and was considered to be a high risk factor of dental caries [40]. It would have been more useful to analyse the effects of carbonated soft drinks and fruit juices separately as it has been reported that the effect of fruit juices on enamel demineralization was more pronounced than that of carbonated soft drinks due to their resistance to the buffering capacity of neutralising factors [41] and its organic acid content [42]. This was not possible to analyse statistically due to the small number of subjects who consumed either carbonated soft drinks alone or fruit juices alone.

Similar pattern to the impact of the use of carbonated soft drinks and/or fruit juices on the development of WSLs and reported above was also found for the use of sugary foods. It has been reported that the consumption of carbohydrate alone does not necessarily increase the risk of caries [1]. Therefore the effect of the carbohydrates in foods on WSLs found in the present study was due to the presence of other factors such as an inadequate $\mathrm{OH}$, increased consumption of carbonated soft drinks and/or fruit juices as well as the increased consumption of the carbohydrates in foods.

However the findings of this study in terms of the impact of sugary foods on the incidence of WSLs should be interpreted with caution. Patients were asked to quantify the frequency of consumption of sugary foods on average per week throughout their entire course of treatment, which may not be accurate. In addition, patients may or may not have been entirely truthful when asked about their dieting habits in relation to high sugar 'junk' foods. Furthermore, an important factor was not determined, the time of consumption, which may be as important as the diet itself. Eating high sugar foods regularly throughout the day places the tooth surfaces under continuing sugar challenge for a longer period of time compared to those who may consume high sugar foods only at mealtimes, raising the risk of WSLs formation $[\underline{9}, \underline{10}]$. Lastly, since WSLs are multifactorial in their development, it may have been better to study patient diet as a whole combining together high risk food groups, rather than studying the effect of each high risk food on the incidence of WSLs as was done in this study.

\section{CONCLUSIONS}

The incidence of WSLs at Aberdeen Dental Hospital was $42 \%$.

The incidence of WSLs in males was significantly higher than in females with males were almost 3 times more likely to form WSLs compared with females. However, ideally a larger sample would be required to make a firm conclusion with regards to the difference in the incidence of WSL between sexes.

There was a symmetry in the incidence of WSLs. The maxillary anterior teeth were statistically significantly more affected than the mandibular anterior teeth. The maxillary lateral incisors and canines were the most affected teeth. The most affected tooth surface location in both dental arches was the gingival margin.

The following risk factors were found to have statistically significant effect on the development of new WSLs: treatment length $>36$ months, inadequate oral hygiene during orthodontic treatment, lack of regular use of fluoride mouthwash during orthodontic treatment, the use of carbonated soft drinks/fruit juices and/or sugary foods four times or more a week.

\section{ACKNOWLEDGMENTS AND DISCLOSURE STATEMENTS}

The author report no conflicts of interest related to this study. The author would like to thank Kim-Weng Tan (Dental School, University of Aberdeen) for his help in the collection of some of the data and Dr. Tatiana Macfarlane (Dental School, University of Aberdeen) for her comments on the manuscript.

\section{REFERENCES}

1. Chang HS, Walsh LJ, Freer TJ. Enamel demineralization during orthodontic treatment. Aetiology and prevention. Aust Dent J. 1997 Oct;42(5):322-7. Review. [Medline: 9409049] [doi: 10.1111/j.1834-7819.1997.tb00138.x]

2. Featherstone JD. The continuum of dental caries--evidence for a dynamic disease process. J Dent Res. 2004;83 Spec No C:C39-42. Review. [Medline: 15286120] [doi: 10.1177/154405910408301S08]

3. Torlakovic L, Klepac-Ceraj V, Ogaard B, Cotton SL, Paster BJ, Olsen I. Microbial community succession on developing lesions on human enamel. J Oral Microbiol. 2012;4. doi: 10.3402/jom.v4i0.16125. Epub 2012 Mar 14. [Medline: 22432048] [PMC free article: 3307376] [doi: 10.3402/jom.v4i0.16125]

4. Benson PE, Shah AA, Millett DT, Dyer F, Parkin N, Vine RS. Fluorides, orthodontics and demineralization: a systematic review. J Orthod. 2005 Jun;32(2):102-14. Review. [Medline: 15994984] [doi: 10.1179/146531205225021033] 
5. Ogaard B, Rølla G, Arends J. Orthodontic appliances and enamel demineralization. Part 1. Lesion development. Am J Orthod Dentofacial Orthop. 1988 Jul;94(1):68-73. [Medline: 3164585] [doi: 10.1016/0889-5406(88)90453-2]

6. Shungin D, Olsson AI, Persson M. Orthodontic treatment-related white spot lesions: a 14-year prospective quantitative follow-up, including bonding material assessment. Am J Orthod Dentofacial Orthop. 2010 Aug;138(2):136.e1-8; discussion 136-7. doi: 10.1016/j.ajodo.2009.05.020. [Medline: 20691346]

7. Hojo S, Komatsu M, Okuda R, Takahashi N, Yamada T. Acid profiles and $\mathrm{pH}$ of carious dentin in active and arrested lesions. J Dent Res. 1994 Dec;73(12):1853-7. [Medline: 7814758$]$

8. Takahashi N, Yamada T. Acid-induced acid tolerance and acidogenicity of non-mutans streptococci. Oral Microbiol Immunol. 1999 Feb;14(1):43-8. [Medline: 10204479] [doi: 10.1034/j.1399-302X.1999.140105.x]

9. Edgar WM. The role of saliva in the control of $\mathrm{pH}$ changes in human dental plaque. Caries Res. 1976;10(4):241-54. [Medline: 7356] [doi: 10.1159/000260206]

10. Higham SM, Edgar WM. Human dental plaque $\mathrm{pH}$, and the organic acid and free amino acid profiles in plaque fluid, after sucrose rinsing. Arch Oral Biol. 1989;34(5):329-34. [Medline: 2597027] [doi: 10.1016/0003-9969(89)90105-2]

11. Featherstone JD. The science and practice of caries prevention. J Am Dent Assoc. 2000 Jul;131(7):887-99. Review. [Medline: 10916327] [doi: 10.14219/jada.archive.2000.0307]

12. Kidd E. The implications of the new paradigm of dental caries. J Dent. 2011 Dec;39 Suppl 2:S3-8. Epub 2011 Nov 10. [Medline: 22085623] [doi: 10.1016/j.jdent.2011.11.004]

13. Chapman JA, Roberts WE, Eckert GJ, Kula KS, González-Cabezas C. Risk factors for incidence and severity of white spot lesions during treatment with fixed orthodontic appliances. Am J Orthod Dentofacial Orthop. 2010 Aug;138(2):18894. [Medline: 20691360] [doi: 10.1016/j.ajodo.2008.10.019]

14. Artun J, Brobakken BO. Prevalence of carious white spots after orthodontic treatment with multibonded appliances. Eur J Orthod. 1986 Nov;8(4):229-34. [Medline: $\underline{3466795}$ ] [doi: 10.1093/ejo/8.4.229]

15. Gorelick L, Geiger AM, Gwinnett AJ. Incidence of white spot formation after bonding and banding. Am J Orthod. 1982 Feb;81(2):93-8. [Medline: 6758594] [doi: 10.1016/0002-9416(82)90032-X]

16. Ogaard B. Prevalence of white spot lesions in 19-year-olds: a study on untreated and orthodontically treated persons 5 years after treatment. Am J Orthod Dentofacial Orthop. 1989 Nov;96(5):423-7. [Medline: 2816842] [doi: 10.1016/0889-5406(89)90327-2]

17. Mizrahi E. Enamel demineralization following orthodontic treatment. Am J Orthod. 1982 Jul;82(1):62-7. [Medline: 6984291] [doi: 10.1016/0002-9416(82)90548-6]

18. Tufekci E, Dixon JS, Gunsolley JC, Lindauer SJ. Prevalence of white spot lesions during orthodontic treatment with fixed appliances. Angle Orthod. 2011 Mar;81(2):206-10. [Medline: 21208070] [doi: 10.2319/051710-262.1]

19. Boersma JG, van der Veen MH, Lagerweij MD, Bokhout B, Prahl-Andersen B. Caries prevalence measured with QLF after treatment with fixed orthodontic appliances: influencing factors. Caries Res. 2005 Jan-Feb;39(1):41-7. [Medline: 15591733] [doi: 10.1159/000081655]

20. Lucchese A, Gherlone E. Prevalence of white-spot lesions before and during orthodontic treatment with fixed appliances. Eur J Orthod. 2013 Oct;35(5):664-8. doi: 10.1093/ejo/cjs070. Epub 2012 Oct 8. [Medline: 23045306] [doi: 10.1093/ejo/cjs070]

21. Mizrahi E. Surface distribution of enamel opacities following orthodontic treatment Am J Dentofacial Orthop. 1983 Oct;84(4):323-31. [Medline: 6605091$]$

22. Fejerskov O, Thylstrup A, Larsen MJ. Rational use of fluorides in caries prevention. A concept based on possible cariostatic mechanisms. Acta Odontol Scand. 1981;39(4):241-9. Review. [Medline: 7034449]

23. Margolis HC, Moreno EC. Physicochemical perspectives on the cariostatic mechanisms of systemic and topical fluorides. J Dent Res. 1990 Feb;69 Spec No:606-13; discussion 634-6. Review. [Medline: 2179321]

24. O'Reilly MM, Featherstone JD. Demineralization and remineralization around orthodontic appliances: an in vivo study. Am J Orthod Dentofacial Orthop. 1987 Jul;92(1):33-40. [Medline: $\underline{3300270}$ ] [doi: 10.1016/0889-5406(87)90293-9]

25. British Fluoridation Society. The extent of water fluoridation. In: One in a Million. The Facts About Water Fluoridation. 2nd ed. London, UK: The British Fluoridation Society, The UK Public Health Association, The British Dental Association, and The Faculty of Public Health; 2004: 55-80. Available at: http://www.bfsweb.org/onemillion/09\%200ne\%20in\%20 a $\% 20$ Million\%20-\%20The\%20Extent\%20of\%20Fluoridation.pdf. (Accessed on 2nd December, 2013).

26. Ogaard B, Rølla G, Arends J, ten Cate JM. Orthodontic appliances and enamel demineralization. Part 2. Prevention and treatment of lesions. Am J Orthod Dentofacial Orthop. 1988 Aug;94(2):123-8. [Medline: 3165239] [doi: 10.1016/0889-5406(88)90360-5]

27. Hadler-Olsen S, Sandvik K, El-Agroudi MA, Øgaard B. The incidence of caries and white spot lesions in orthodontically treated adolescents with a comprehensive caries prophylactic regimen--a prospective study. Eur J Orthod. 2012 Oct;34(5):633-9. Epub 2011 Jul 12. [Medline: 21750245]

28. Kühnisch J, Goddon I, Berger S, Senkel H, Bücher K, Oehme T, Hickel R, Heinrich-Weltzien R. Development, methodology and potential of the new Universal Visual Scoring System (UniViSS) for caries detection and diagnosis. Int J Environ Res Public Health. 2009 Sep;6(9):2500-9. [Medline: 19826559] [PMC free article: 2760425] [doi: 10.3390/ijerph6092500] 
29. Julien KC, Buschang PH, Campbell PM. Prevalence of white spot lesion formation during orthodontic treatment. Angle Orthod. 2013 Jul;83(4):641-7. Epub 2013 Jan 4. [Medline: 23289733] [doi: 10.2319/071712-584.1]

30. Lovrov S, Hertrich K, Hirschfelder U. Enamel Demineralization during Fixed Orthodontic Treatment - Incidence and Correlation to Various Oral-hygiene Parameters. J Orofac Orthop. 2007 Sep;68(5):353-63. [Medline: 17882363] [doi: 10.1007/s00056-007-0714-1]

31. Zachrisson BU, Zachrisson S. Caries incidence and orthodontic treatment with fixed appliances. Scand J Dent Res. 1971;79(3):183-92. [Medline: 5285724]

32. Geiger AM, Gorelick L, Gwinnett AJ, Griswold PG. The effect of a fluoride program on white spot formation during orthodontic treatment. Am J Orthod Dentofacial Orthop. 1988 Jan;93(1):29-37. [Medline: 3276146] [doi: 10.1016/0889-5406(88)90190-4]

33. Alcouffe F. Oral hygiene behavior: differences between men and women. Clin Prev Dent. 1989 May-Jun;11(3):6-10. [Medline: 2605860]

34. Ostberg AL, Halling A, Lindblad U. Gender differences in knowledge, attitude, behavior and perceived oral health among adolescents. Acta Odontol Scand. 1999 Aug;57(4):231-6. [Medline: 10540935] [doi: 10.1080/000163599428832]

35. Sakki TK, Knuuttila ML, Anttila SS. Lifestyle, gender and occupational status as determinants of dental health behavior. J Clin Periodontol. 1998 Jul;25(7):566-70. [Medline: 9696257] [doi: 10.1111/j.1600-051X.1998.tb02489.x]

36. Stratemann MW, Shannon IL. Control of decalcification in orthodontic patients by daily self-administered application of a water-free 0.4 per cent stannous fluoride gel. Am J Orthod. 1974 Sep;66(3):273-9. [Medline: 4528489] [doi: $10.1016 / 0002-9416(74) 90291-7$ ]

37. Kalha A. Some evidence that fluoride during orthodontic treatment reduces occurrence and severity of white spot lesions. Evid Based Dent. 2004;5(4):98-9. [Medline: 15608710]

38. Ireland AJ, McGuinness N, Sherriff M. An investigation into the ability of soft drinks to adhere to enamel. Caries Res. 1995;29(6):470-6. [Medline: 8556751] [doi: 10.1159/000262117]

39. Ismail AI, Burt BA, Eklund SA. The cariogenicity of soft drinks in the United States. J Am Dent Assoc. 1984 Aug;109(2):241-5. [Medline: 6590604$]$

40. Sohn W, Burt BA, Sowers MR. Carbonated soft drinks and dental caries in the primary dentition. J Dent Res. 2006 Mar;85(3):262-6. [Medline: 16498075] [doi: 10.1177/154405910608500311]

41. Edwards M, Creanor SL, Foye RH, Gilmour WH. Buffering capacities of soft drinks: the potential influence on dental erosion. J Oral Rehabil. 1999 Dec;26(12):923-7. [Medline: 10620154] [doi: 10.1046/j.1365-2842.1999.00494.x]

42. Larsen MJ, Nyvad B. Enamel erosion by some soft drinks and orange juices relative to their $\mathrm{pH}$, buffering effect and contents of calcium phosphate. Caries Res. 1999;33(1):81-7. [Medline: 9831784] [doi: 10.1159/000016499]

\author{
To cite this article: \\ Khalaf K. Factors Affecting the Formation, Severity and Location of White Spot Lesions during Orthodontic Treatment with \\ Fixed Appliances. \\ J Oral Maxillofac Res 2014;5(1):e4 \\ URL: http://www.ejomr.org/JOMR/archives/2014/1/e4/v5n1e4ht.pdf \\ doi: $\underline{10.5037 / j o m r .2014 .5104}$
}

Copyright (C) Khalaf K. Published in the JOURNAL OF ORAL \& MAXILLOFACIAL RESEARCH (http://www.ejomr. org), 1 April 2014.

This is an open-access article, first published in the JOURNAL OF ORAL \& MAXILLOFACIAL RESEARCH, distributed under the terms of the Creative Commons Attribution-Noncommercial-No Derivative Works 3.0 Unported License, which permits unrestricted non-commercial use, distribution, and reproduction in any medium, provided the original work and is properly cited. The copyright, license information and link to the original publication on (http://www.ejomr.org) must be included. 